\title{
Temporal and spatial variations in ionospheric electron density profiles over South Africa during strong magnetic storms
}

\author{
Y. B. Yao ${ }^{1,2}$, P. Chen ${ }^{1,3}$, S. Zhang ${ }^{1}$, and J. J. Chen ${ }^{1}$ \\ ${ }^{1}$ School of Geodesy and Geomatics, Wuhan University, Wuhan 430079, China \\ ${ }^{2}$ Key Laboratory of Geospace Environment and Geodesy, Ministry of Education, Wuhan University, Wuhan 430079, China \\ ${ }^{3}$ College of Geomatics, Xi' an University of Science and Technology, Xi' an 710054, China
}

Correspondence to: Y. B. Yao (ybyao@whu.edu.cn)

Received: 14 October 2012 - Published in Nat. Hazards Earth Syst. Sci. Discuss.: -

Revised: 9 January 2013 - Accepted: 10 January 2013 - Published: 15 February 2013

\begin{abstract}
Observations from the South African TrigNet global navigation satellite system (GNSS) and vertical total electron content (VTEC) data from the Jason-1 satellite were used to analyze the variations in ionospheric electron density profiles over South Africa before and after the severe geomagnetic storms on 15 May 2005. Computerized ionospheric tomography (CIT) was used to inverse the 3-D structure of ionospheric electron density and its response to the magnetic storms. Inversion results showed that electron density significantly increased at 10:00 UT, 15 May compared with that at the same period on 14 May. Positive ionospheric storms were observed in the inversion region during the magnetic storms. Jason-1 data show that the VTEC observed on descending orbits on 15 May significantly increased, whereas that on ascending orbits only minimally changed. This finding is identical to the CIT result.
\end{abstract}

\section{Introduction}

A geomagnetic storm is a complex process that originates from solar wind and the magnetosphere. It is one of the most important phenomena related to solar wind and solar energetic particles. Geomagnetic storms can cause severe global ionospheric disturbance and affect the neutral atmosphere, including the troposphere and middle atmosphere. Accompanied by magnetic storms, ionospheric total electron content (TEC), ionospheric F2 layer critical frequency, and other ionospheric parameters exhibit drastic changes that can last for several hours to a few days. Appleton and Ingram (1935) first defined strong ionospheric disturbances during geomagnetic storms as ionospheric storms. Numerous scholars have conducted research on such storms, but definitive findings have yet to be obtained. Studies on ionospheric storms remain a challenge for ionospheric researchers (Zhao, 2006).

Considerable research has revealed the fundamental laws of ionospheric storms. Generally, ionospheric storms at high latitudes are mainly negative-phase storms (i.e. the ionospheric electron density is significantly lower than the average ionospheric state), whereas those occurring at low latitudes are primarily positive-phase storms (i.e. the ionospheric electron density significantly greater than average ionospheric state). Whether a specific ionospheric storm is a positive- or negative-phase storm is determined by the local time at which the main phase of the storm occurs. At middle latitudes, if the main phase occurs in the morning, then the ionospheric storm is classified as of positive-phase type. If the main phase occurs in the afternoon, the ionospheric storm is categorized as a weak positive-phase storm; an intense negative-phase storm occurs the following day. The occurrence of the main storm phase at nighttime typically generates a negative-phase storm the next day (Balan and Rao, 1990). Kelley et al. (2004) suggested that daytime eastward prompt penetration electric field (PPEF) that produces negative storms in $N_{\max }$ and TEC at equatorial latitudes through enhanced plasma fountain (Balan et al., 2009) could also be the main driver of the positive storms at higher latitudes. However, modeling studies later revealed that the PPEF alone is unlikely to produce the positive storms and equatorward neutral winds alone (Balan et al., 2009) or together with PPEF (Lin et al., 2005; Lu et al., 2012) can produce the 
positive storms. The physical mechanisms of why the eastward PPEF is unlikely to produce the positive storms, and how the neutral winds produce the positive storms have been reported recently (Balan et al., 2010, 2011).

Early ionospheric storm research was based primarily on single-station observations, later gradually developing into studies that feature local area observations from multiple stations and global station networks. Paul et al. (1977) used observations from 35 ionospheric stations and seven geomagnetic stations in the Asia-Pacific region to investigate the ionospheric storm that occurred on 4-5 August 1972. The results showed that electron density sharply increased after the initial phase of the magnetic storm, and the peak occurred between geomagnetic latitudes $20^{\circ}$ and $45^{\circ}$. Using observations from 40 ionosonde stations and TEC data from 12 GPS stations, Yeh et al. (1994) investigated the global ionospheric response during the strong geomagnetic storm in October 1989. Szuszczewicz et al. (1998) used observations from 53 global ionosonde stations to investigate the ionospheric response during three strong geomagnetic storms in September 1989. The results showed that the hmF2 and $\mathrm{NmF} 2$ were related to the local time, latitude, and time of occurrence of geomagnetic storms. Mannucci et al. (2005) studied the ionospheric changes during the "Halloween" super magnetic storm in 29-30 October 2003. The dayside ionospheric TEC on 29 and 30 October increased by $40 \%$ and $250 \%$, respectively. The significant ionospheric change may have been caused by the eastward equatorial electric field during the storm. Essex et al. (1981) used data from 18 global stations to study the ionospheric response after the geomagnetic storm on 17 June 1972, and compared it with the ionospheric response after the magnetic storm on 17 December 1971.

A number of studies focused on the statistical properties of ionospheric storms. Balan et al. (2010) used TEC and $N_{\max }$ data to investigate the time of occurrence and strength of the ionospheric response at low latitudes after the 60 magnetic storms that occurred from 1968 to 1972. Mendillo and Narvaez $(2009,2010)$ used $N_{\max }$ data to study the ionospheric changes after the 206 magnetic storms that occurred from 1964 to 1976. Lekshmi et al. (2011) used data from two ionosonde stations in Japan and the United States to determine the ionospheric response characteristics of the 584 magnetic storms of two solar cycles that occurred from 1985 to 2005. Some scholars used models to simulate the generation of ionospheric storms and study the physical mechanisms of such storms (Burns et al., 1995; Fuller-Rowell et al., 1994; Lin et al., 2005; Lu et al., 2008; Richmond and Matsushita, 1975).

The late 1970s saw the rise of GNSS, which improved ionospheric sounding technology. Since then, ionospheric research has gone through rapid development. GNSS represents a new technology that obtains accurate TEC values from satellites and receivers, and continuously monitors ionospheric changes over a wide geographical range.
GNSS-based computerized ionospheric tomography (CIT) technology was then gradually developed to aid the understanding of the full range of temporal and spatial distributions of ionospheric electron density. New CIT technology enables the 3-D and 4-D reconstruction of the spatial structure of the ionosphere. Using GPS data from Chinese GNSS stations and CIT, Wen et al. (2007) studied the temporal and spatial changes in ionospheric electron density profiles over China during the magnetic storm on 18 and $21 \mathrm{Au}-$ gust 2003. Thampi et al. (2009) used CIT to investigate summer night ionospheric anomalies that occur at middle latitudes. Yao et al. (2012a) used CIT technology to inverse the 3-D variations in ionospheric electron density before the Japan $M_{\mathrm{w}}=9.0$ earthquake on 11 March 2011. The authors excluded the effects of magnetic storms in their study. The results showed that significant positive anomalies in the ionospheric electron density profile could be detected before the earthquake. Yao et al. (2012b) investigate the unusual ionospheric total electron content (TEC) variations which occurred before the global $M=7.0+$ earthquakes in 2010, and confirmed that the earthquake-related ionospheric anomalies discussed in the paper occurred 0-2 days before the associated earthquakes and in the afternoon to sunset. Yizengaw et al. (2005) used ground-based and satellite data to investigate the ionospheric response in the Southern Hemisphere during the magnetic storms on 31 March 2001. The authors used the chain of GPS receiver stations near $150^{\circ} \mathrm{E}$ to inverse the ionospheric electron density variations at $150^{\circ} \mathrm{E}$ longitude during the storms. Mai and Kiang (2009) used CIT technology to inverse the ionospheric anomalies that occurred after the 2004 Sumatra tsunami.

To compensate for the lack of GNSS tracking stations in marine areas, researchers used altimetry satellite data to directly access TEC trends over the global ocean (Dumont et al., 2009; Fu et al., 1994; Jee et al., 2004).

In the current work, data derived by GNSS CIT technology and the Jason-1 ocean altimetry satellite were used to analyze the spatial and temporal variations in ionospheric electron density before and after the severe magnetic storm on 15 May 2005. The response of ionospheric electron density to magnetic storms is also discussed.

\subsection{Geomagnetic environment in solar and interplanetary space}

Solar activity was intense after 10 May 2005. From 10 to 13 May, six $M$-class flares were observed, among which an $M=8.0$ flare occurred on 13 May at 16:13 UT to 17:28 UT. The giant storm on 15 May was directly caused by the coronal mass ejections produced by the $M=8.0$ flare. Figure 1 shows the satellite records of interplanetary magnetic field strength, the $\mathrm{Bz}$ component of the interplanetary magnetic field, and solar wind speed, as well as the $\mathrm{Kp}$, Dst, and $\mathrm{AE}$ indices recorded by geomagnetic stations on Earth. An intense magnetic storm occurred on 15 May, 
and the Dst variation showed that this storm was a suddencommencement magnetic storm. Solar wind speed drastically increased at 00:00 UT on 15 May. At 10:00 UT, solar wind speed exceeded $900 \mathrm{~km} \mathrm{~s}^{-1}$, twice the speed of that occurring at the same period the day before. The Bz component of the interplanetary magnetic field reached $-40 \mathrm{nT}$ at around 06:00 UT on 15 May. The signature of the subsequent $\mathrm{Bz}$ component rapidly changed to north and continued on this course for a while, then shifted between the north and south directions. The dramatic changes in the interplanetary magnetic field triggered a magnetic storm with a sudden commencement time at 06:12 UT. Dst rapidly increased from $4 \mathrm{nT}$ to $45 \mathrm{nT}$ at 03:00 UT on 15 May, then quickly decreased at 06:00 UT. The main phase of the storm occurred at 08:00 UT, when the Dst index was $-263 \mathrm{nT}$ and the Kp index was $8+$. Simultaneously, the AE index rapidly increased, representing the considerable solar energy injected into the ionosphere. The Dst index then gradually increased, and the magnetic storms reached the recovery phase. On 20 May, the Dst index returned to the normal state before the magnetic storm occurred.

\subsection{Selection and processing of GNSS observation data}

To study the temporal and spatial distributions of the ionospheric disturbances at low-latitude regions in the Southern Hemisphere during the magnetic storm, we used data from the South African TrigNet network data to inverse the 3$\mathrm{D}$ distribution of local ionospheric electron density before and after the magnetic storm on 15 May 2005. We then analyzed the temporal and spatial variations in ionospheric electron density in the abnormal space environment. TrigNet is a continuously operating GNSS network that covers South Africa; the distance between the base stations of TrigNet is $200 \mathrm{~km}$ to $300 \mathrm{~km}$. In 2005, TrigNet was a network comprising 23 continuous tracking stations. The distribution of these tracking stations is shown in Fig. 2. We inverted the variations in ionospheric electron density during the magnetic storm using dual-frequency GPS observation data from 23 base stations from 14 to 15 May 2005. The time interval of the dual-frequency GPS observation data is $30 \mathrm{~s}$.

When CIT technology is used to inverse the temporal and spatial variations in ionospheric electron density in anomalous space environments, the first step is to preprocess original observation data. We used the Turbo Edit method (Blewitt, 1990) to detect and repair the errors and cycle slips in the GPS observation data. Then, the geometry-free pseudorange and carrier phase were used to come up with basic observations. Finally, the STEC was calculated along the signal propagation path between each satellite and receiver. In this paper, the cut-off angle used was $10^{\circ}$. In accordance with the influence of system hardware delays, we employed a typical approach, in which we constructed a single-layer ionospheric model, resolved satellite hardware delays, and used model parameters to solve receiver hardware delays as unknown

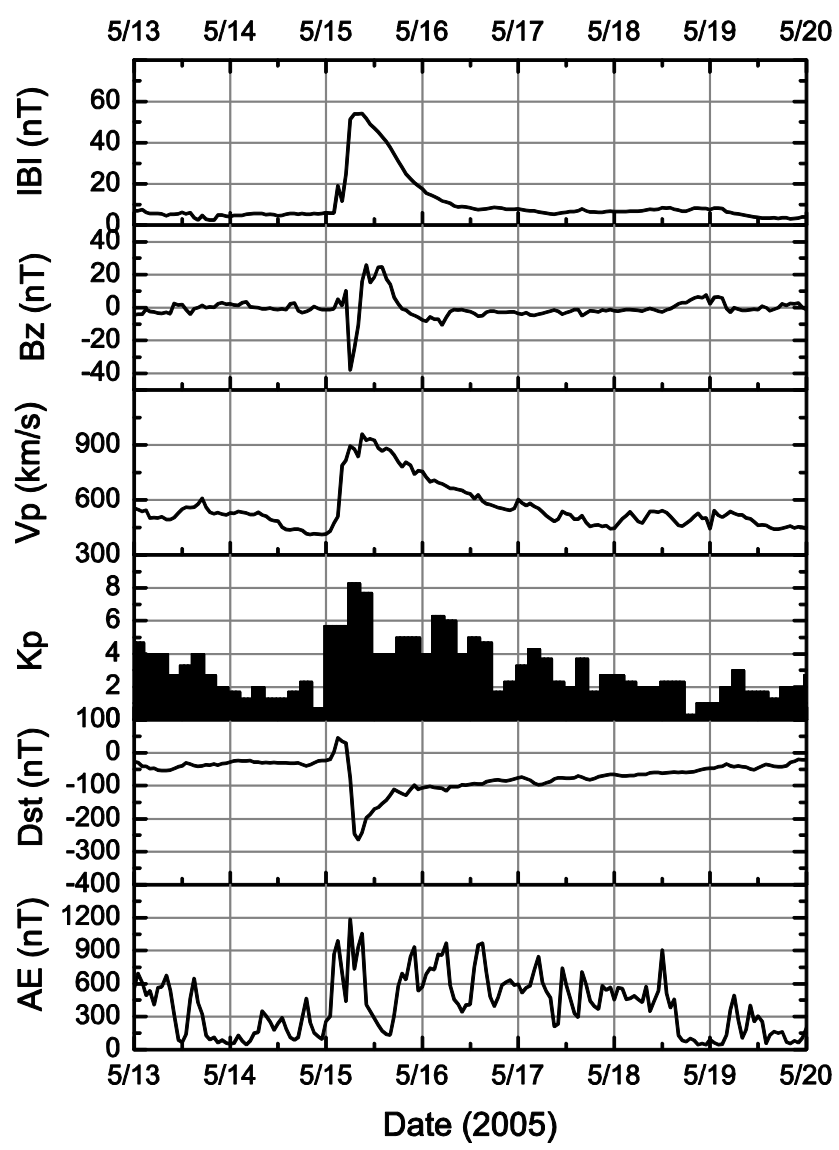

Fig. 1. Solar and geomagnetic field parameters on 13 and 20 May 2005. The satellite records of interplanetary magnetic field strength, the Bz component of the interplanetary magnetic field, and solar wind speed, as well as the Kp, Dst, and AE indices recorded by geomagnetic stations are shown from top to bottom.

parameters. To derive precise results, we used two-day data to solve receiver hardware delays and then obtained the absolute STEC.

The ionospheric TEC is the line integral electron density on the signal propagation path. It is expressed as

$\mathrm{TEC}=\int_{l} N e(\boldsymbol{r}, t) \mathrm{d} s$,

where $\mathrm{Ne}$ is the electron density along the signal propagation path $l$. GNSS-based ionospheric CIT uses a series of TECs along $l$ to inverse the temporal and spatial distributions of ionospheric electron density. After discretizing Eq. (1) in the inversion process, we obtained

$\boldsymbol{y}=A \cdot \boldsymbol{x}+\boldsymbol{\varepsilon}$,

where $A$ is the coefficient matrix constituted by intercepts when GNSS signals pass through the ionosphere; $\boldsymbol{y}$ denotes the observation vector constituted by the TEC along each 


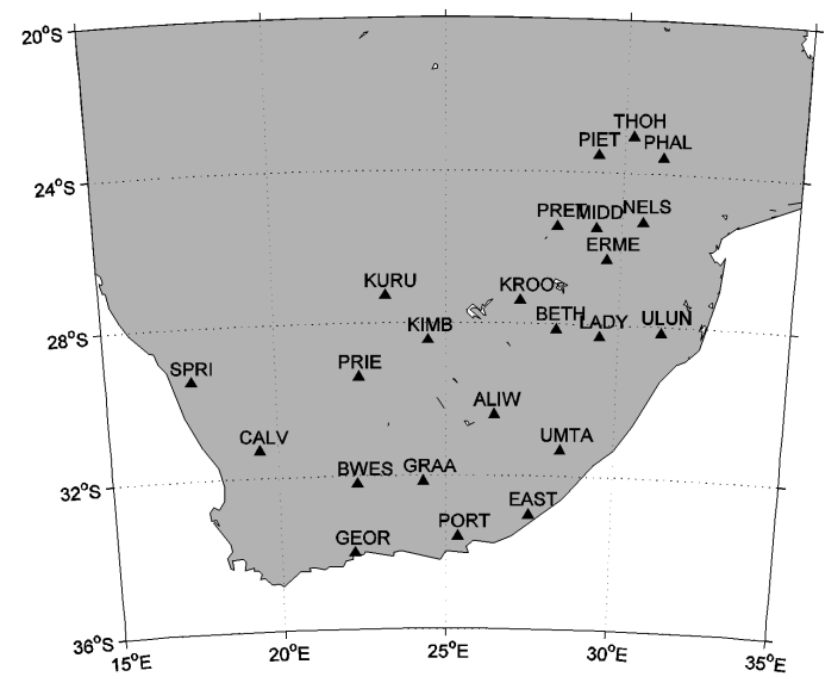

Fig. 2. Distribution of TrigNet sites.

GNSS signal propagation path; $\boldsymbol{x}$ represents the parameter vector constituted by the electron density of each pixel in the image of the ionosphere; $\boldsymbol{\varepsilon}$ is the noise vector of observations.

Using Eq. (2) for ionospheric CIT indicates that coefficient matrix $A$ is a huge sparse matrix and usually rank deficient. The most common approach is to use an empirical model (e.g. the international reference ionosphere model) as the initial iteration value to obtain the electron density of the inversion region.

Given the non-negativity of electron density, we inverted it by the multiplicative algebraic reconstruction technique. The iterative formula can be written as

$x_{j}^{(k+1)}=x_{j}^{(k)}\left(\frac{y_{i}}{\left\langle a_{i}, x^{(k)}\right\rangle}\right)^{\frac{\gamma_{0} \cdot a_{i j}}{A}}$,

where $x^{(k)}$ is the unknown parameter of the $k$-th iteration; $a_{i}$ is the $i$-th row of $A ; \gamma_{0}$ denotes the relaxation factor of each iteration, with $0<\gamma_{0}<1$.

To elucidate the features of the ionospheric disturbances during the magnetic storm, we used the GNSS observation data provided by the South African TrigNet. These data were also used to process the inversion. The inversion region is between $16^{\circ} \mathrm{E}$ to $32^{\circ} \mathrm{E}$ and $22^{\circ} \mathrm{S}$ to $36^{\circ} \mathrm{S}$ at a height of $100 \mathrm{~km}$ to $1000 \mathrm{~km}$. The size of the grid, which is $50 \mathrm{~km}$ high, is $2^{\circ}$ both in latitude and longitude regions. Thus the ionosphere over South Africa is divided into 8, 7, and 19 grids along longitude, latitude, and height.

\section{CIT results during storms}

To study the temporal and spatial variations in ionospheric electron density before and after the magnetic storm, we present the electron density distribution at different altitudes at 10:00 UT on 14-15 May 2005.

Figure 3 compares the ionospheric electron density at different altitudes at 10:00 UT on 14 and 15 May. The electron density at each altitude at 10:00 UT on 15 May significantly increased compared with the 14 May value, indicating that a positive-phase storm occurred in the ionosphere of the inversion region during the magnetic storm. The maximum electron density at each altitude at 10:00 UT on 15 May increased to $79.3 \%$ on average compared with that on 14 May, during which the electron density at an altitude of $800 \mathrm{~km}$ increased to a maximum of $84.9 \%$. The minimum electron density increased to $30.7 \%$, similar to that at $800 \mathrm{~km}$, which reached a maximum of $38.4 \%$. The peak electron density at an altitude of $300 \mathrm{~km}$ increased from $8.15 \times 10^{11} \mathrm{el} \mathrm{m}^{-3}$ to $1.36 \times 10^{12} \mathrm{el} \mathrm{m}^{-3}$. The electron density distributions during the two days both decreased with increasing altitude.

Figure 4 shows a schematic of the temporal and spatial variations in electron density at an altitude of $350 \mathrm{~km}$ and a time interval of $2 \mathrm{~h}$ from 04:00 UT on 14 May to 20:00 UT on 15 May. Electron density significantly changed over time. For $40 \mathrm{~h}$, electron density generally exhibited a high-to-low trend, significantly increased, and then gradually decreased. On 14 May, geomagnetic field activity was relatively calm, the electron density in the inversion region presented normal diurnal variations over time, and the changes in normal ionospheric electron density were influenced primarily by the sun. The peak electron density was $1.75 \times$ $10^{11} \mathrm{el} \mathrm{m}^{-3}$ at 04:00 UT, increased to $3.45 \times 10^{11} \mathrm{el} \mathrm{m}^{-3}$ at 06:00 UT, then gradually increased and reached a maximum of $6.85 \times 10^{11} \mathrm{el} \mathrm{m}^{-3}$ at 12:00 UT. The maximum electron density lasted $2 \mathrm{~h}$, then gradually decreased to $4.4 \times$ $10^{11} \mathrm{el} \mathrm{m}^{-3}$ at 16:00 UT. It presented a minimum of $1.5 \times$ $10^{11} \mathrm{el} \mathrm{m}^{-3}$ at 02:00 UT on 15 May before beginning to increase again. On 15 May, a strong magnetic storm occurred in the geomagnetic field, after which ionospheric electron density presented significantly abnormal changes. At a similar period on 14 May, the peak electron density at 06:00 UT increased by an insignificant rate of $15.9 \%$, i.e. $4 \times 10^{11} \mathrm{el} \mathrm{m}^{-3}$. At 08:00 UT, peak electron density increased to $7.3 \times 10^{11} \mathrm{el} \mathrm{m}^{-3}$, a value $52 \%$ higher than the increase on 14 May. It presented significantly positive abnormal changes at 10:00 UT and reached $1.2 \times 10^{12} \mathrm{el} \mathrm{m}^{-3}$, a value $81.8 \%$ higher than the increase on 14 May. At 12:00 UT, peak electron density continued to present positive anomalies at $31.4 \%$ greater than those on 14 May. However, the ionospheric electron density in the inversion region presented negative anomalies at almost $6 \%$ less than those on 14 May. At 16:00 UT, peak electron density presented positive anomalies at $37.5 \%$ greater than those on 14 May. At 18:00 UT and 20:00 UT, the anomalies increased to $73.6 \%$ and $22.2 \%$, respectively.

Figure 5 shows the temporal and spatial variations in electron density on the $24^{\circ} \mathrm{E}$ profile from 04:00 UT on 14 May to 20:00 UT on 15 May. Similar to Fig. 4, Fig. 5 shows that 

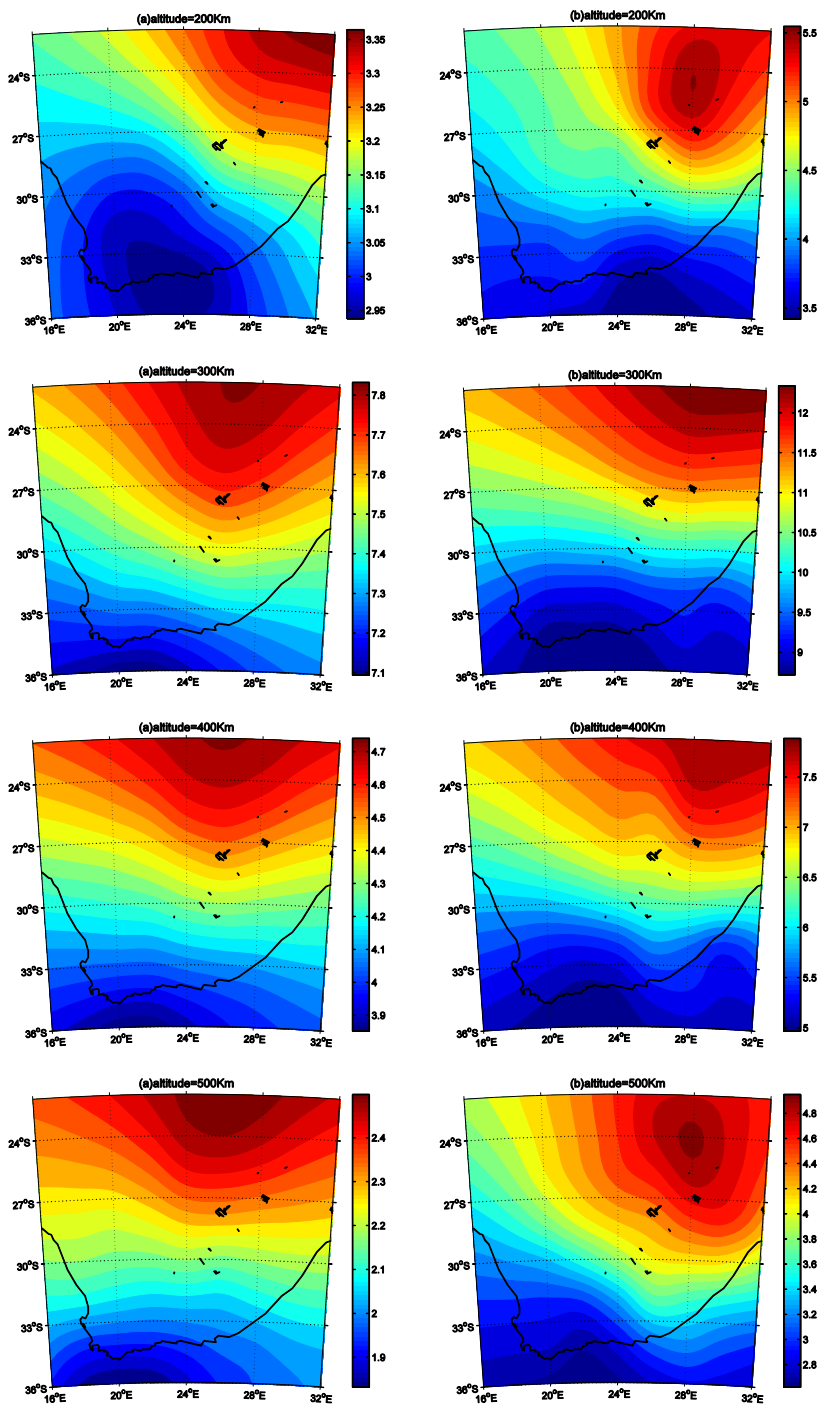

Fig. 3. Electron density at different altitudes at 10:00 UT (13:00 LT) on (a) 14, (b) 15 May 2005 (unit: $10^{11} \mathrm{el} \mathrm{m}^{-3}$ ).

ionospheric electron density presented normal diurnal variations over time on 14 May; it presented violent abnormal changes on 15 May because of the magnetic storm. Electron density began to increase at low latitudes first at 06:00 UT on 14 May, then reached a maximum of $4.59 \times 10^{11} \mathrm{el} \mathrm{m}^{-3}$ at an altitude of $250 \mathrm{~km}$ between $22^{\circ} \mathrm{S}$ and $24^{\circ} \mathrm{S}$. At 10:00 UT, the electron density at any altitude was roughly consistent with that at longitude $24^{\circ} \mathrm{E}$ when peak electron density was $8.04 \times 10^{11} \mathrm{el} \mathrm{m}^{-3}$ at an altitude of $300 \mathrm{~km}$. At 14:00 UT, the ionospheric maximum electron density remained unchanged, but slightly declined to $7.68 \times 10^{11} \mathrm{el} \mathrm{m}^{-3}$ at high latitudes. At 18:00 UT, the electron density significantly declined to $2.47 \times 10^{11} \mathrm{el} \mathrm{m}^{-3}$. The electron density further decreased to $1.6 \times 10^{11} \mathrm{el} \mathrm{m}^{-3}$ from 22:00 UT on 14 May to 02:00 UT on 15 May. The ionosphere began presenting significantly abnormal changes with the magnetic storm at 06:00 UT on
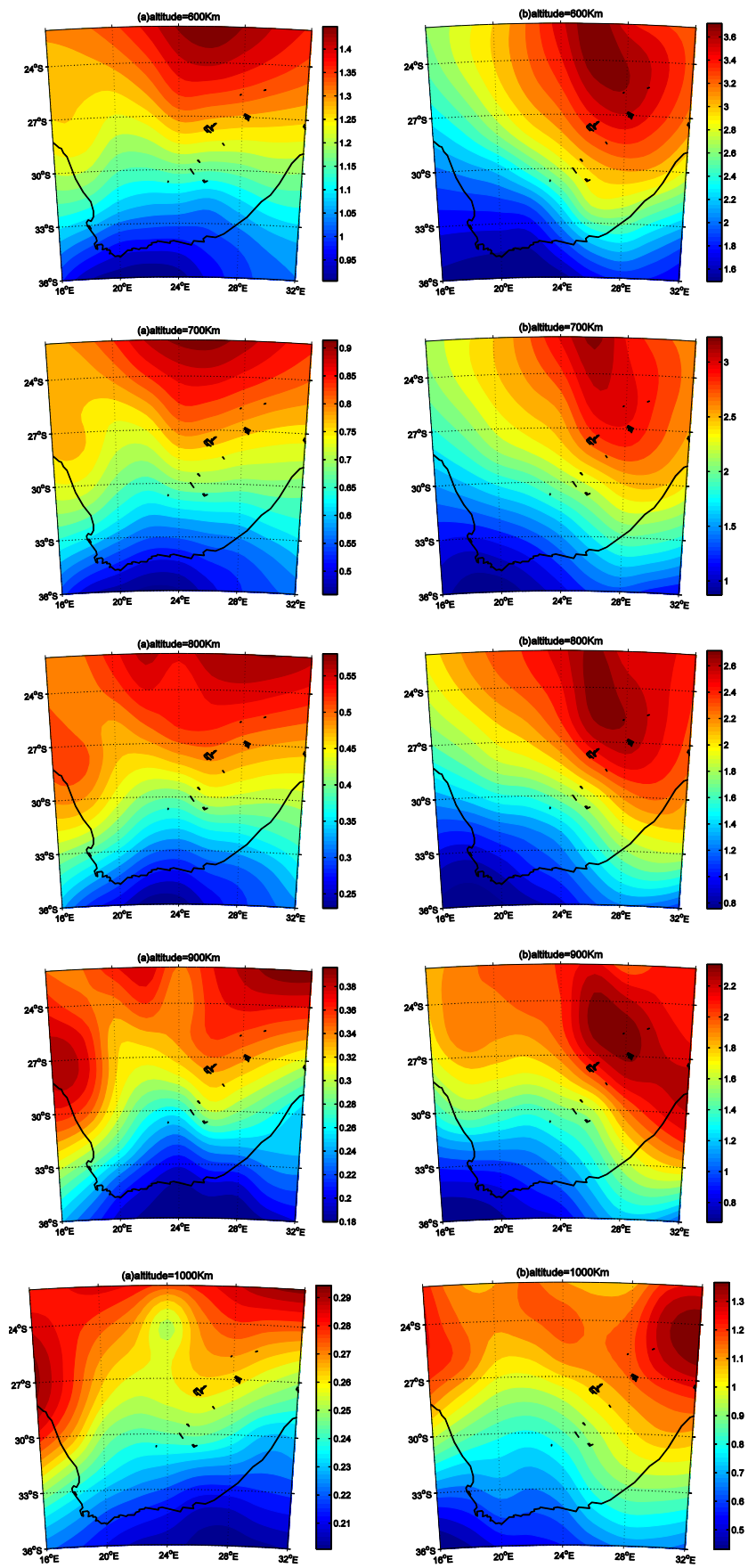

Fig. 3. Continued.

15 May. The anomaly also increased with the continuous development of the magnetic storm. At 06:00 UT, the ionospheric maximum electron density was $5 \times 10^{11} \mathrm{el} \mathrm{m}^{-3}$ at an altitude of $260 \mathrm{~km}$ without significant anomalies compared with the same period on 14 May. At 10:00 UT, however, electron density significantly increased to $1.3 \times 10^{12} \mathrm{el} \mathrm{m}^{-3}$, which is $61.7 \%$ higher than that on 14 May. This value is particularly significant between $22^{\circ} \mathrm{S}$ and $30^{\circ} \mathrm{S}$. The results 

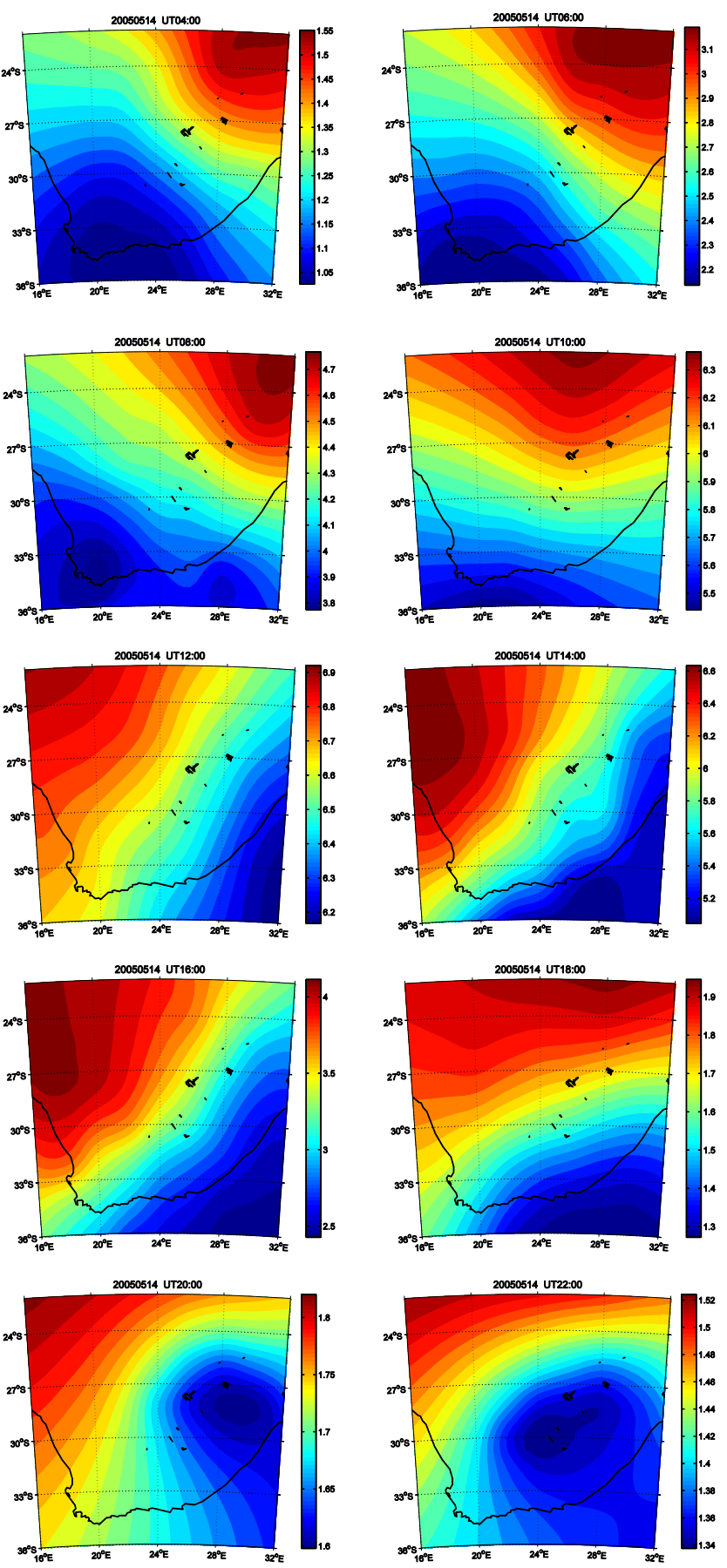

Fig. 4. Map of the electron density changes at an altitude of $350 \mathrm{~km}$ from 04:00 UT on 14 May to 20:00 UT on 15 May (unit: $\left.10^{11} \mathrm{el} \mathrm{m}^{-3}\right)$.

indicate that the ionosphere has apparent positive anomalies. However, Fig. 5 shows that the peak altitude of ionospheric electron density changed little. The slight change is attributed to the fact that the ground-based GNSS observation data and the small volume of radio occultation data used only minimally improved the vertical resolution of the inversion
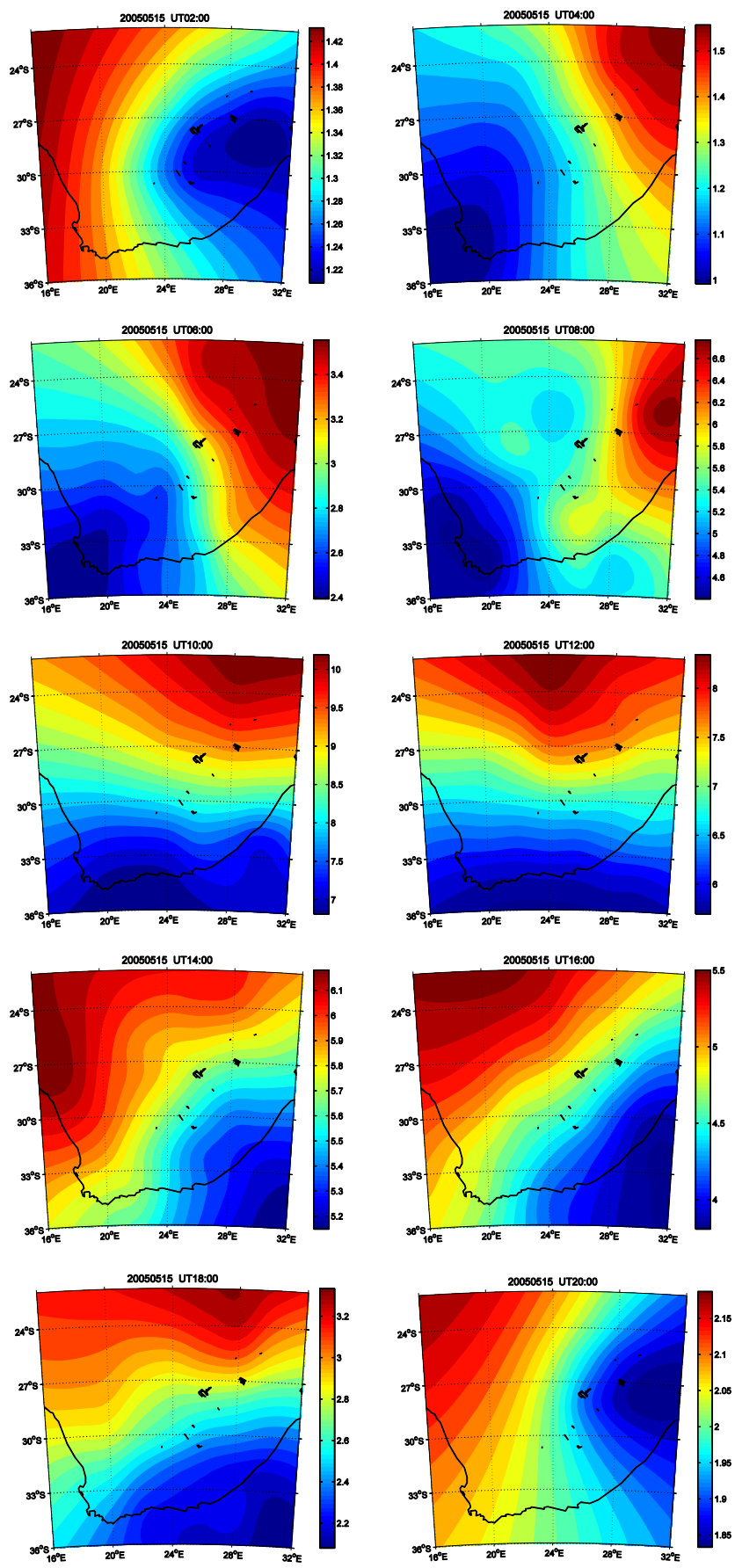

Fig. 4. Continued.

results. The manner by which the vertical resolution of the inversion results is improved is a key issue for further study.

On the basis of the temporal and spatial distribution map of electron density at high altitudes and longitudes (Figs. 4 and 5), we can determine the strong ionospheric disturbances during the magnetic storm and the changes in the characteristics of ionospheric electron density at the middle and low latitudes of the Southern Hemisphere. Ionospheric activity 

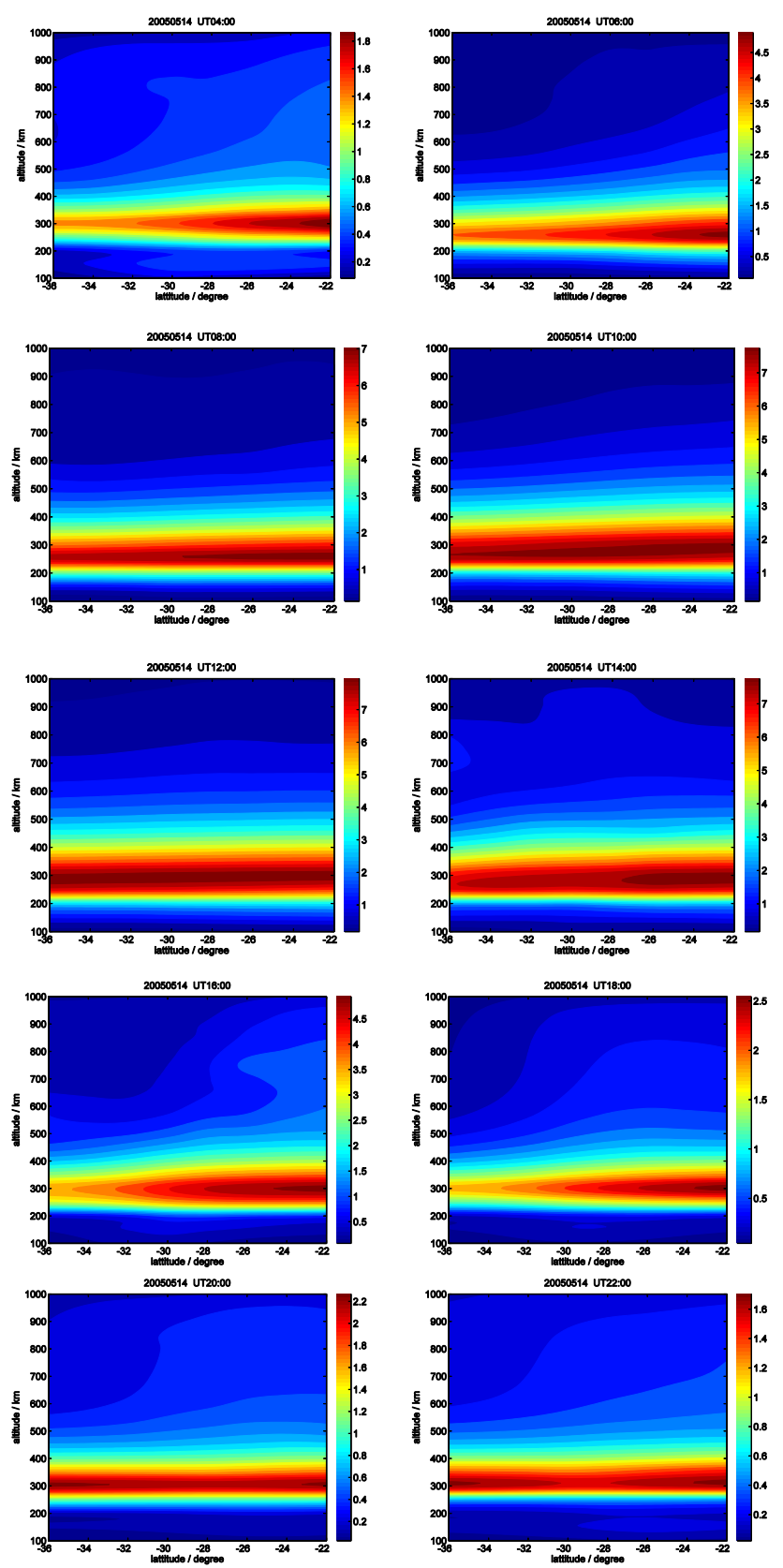

Fig. 5. Map of the electron density changes on the $24^{\circ} \mathrm{E}$ profile from 04:00 UT on 14 May to 20:00 UT on 15 May (unit: $10^{11} \mathrm{el} \mathrm{m}^{-3}$ ).

exhibited a strong relationship with latitude, and total electron density decreased with increasing latitude. At a relatively calm space weather, the ionospheric electron density over the inversion region initially changed from low to high, then from high to low with time, indicating that the changes in ionospheric electron density are related to time. On the basis of the discussion of above, we inverted the ionospheric electron density in South Africa by CIT and regional highprecision GNSS observation data to determine the changes
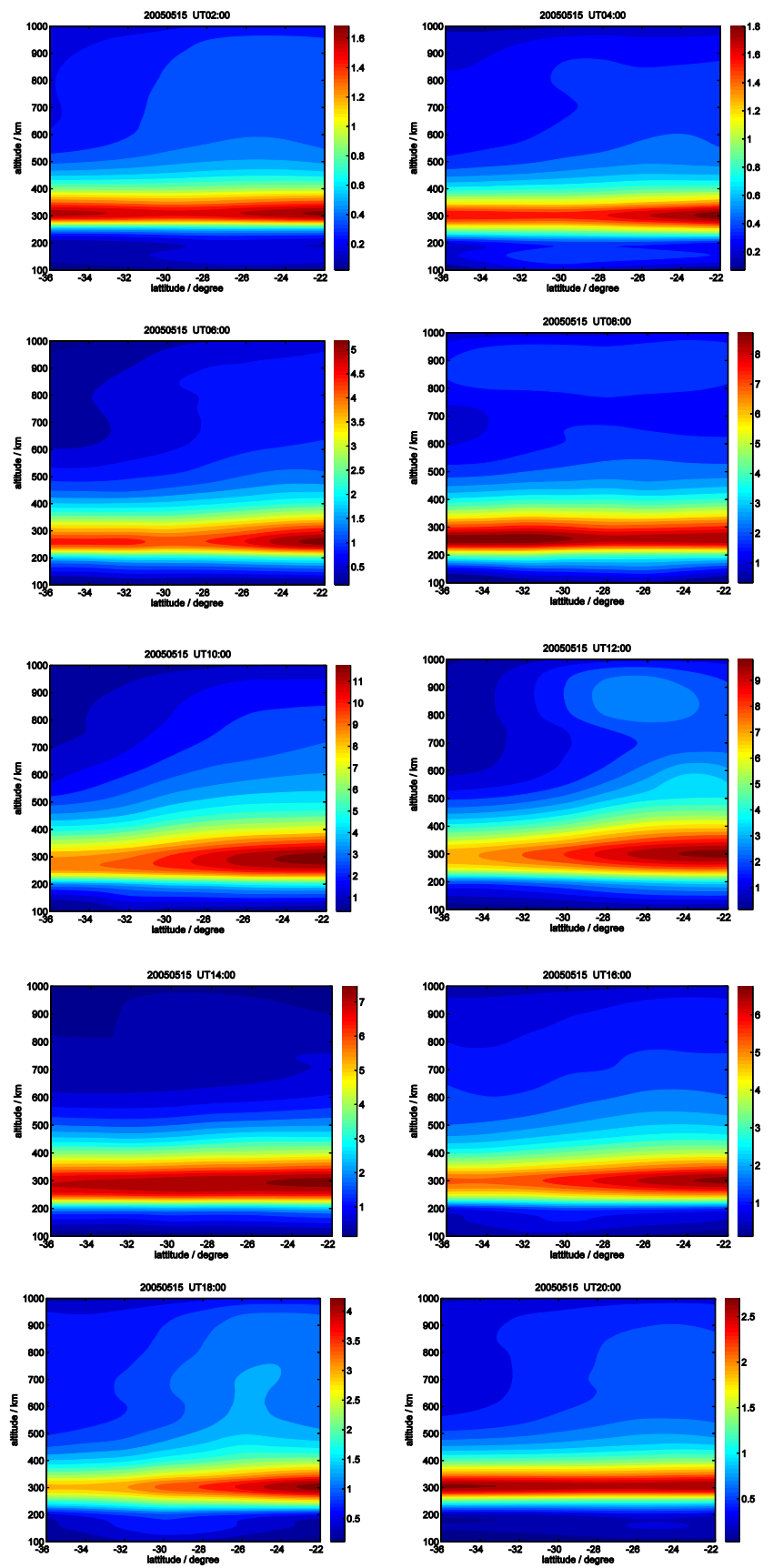

Fig. 5. Continued.

in ionospheric activity, especially the characteristics of the spatial and temporal distributions of the ionosphere during the magnetic storm.

\section{Jason-1 satellite VTEC}

The Jason-1 satellite is an ocean altimetry satellite jointly developed by the French Space Agency (CNES) and the US Space Administration (NASA). The Jason-1 satellite covers 


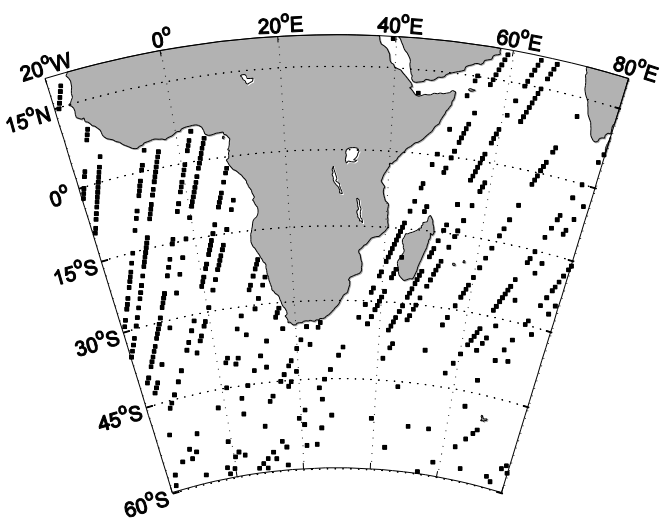

Fig. 6. Ascending orbit data image taken by the Jason-1 satellite from 13 to 18 May 2005.

up to $66^{\circ} \mathrm{N}$ to $66^{\circ} \mathrm{S}$, with an orbit altitude of $1336 \mathrm{~km}$. The satellite takes $112 \mathrm{~min}$ to run a cycle. The radar altimeter on the Jason-1 satellite has dual-band transmission frequency. The major frequency is ku-band and the minor frequency is $\mathrm{C}$-band. The radar altimeter can directly determine TEC in the vertical direction, and has high credibility for low-latitude and equatorial regions.

Using VTEC data obtained by the Jason-1 satellite from 13 to 18 May 2005, we analyzed the changes in ionospheric electron density during the magnetic storm and compared data on VTEC ascending and descending orbits. Figures 6 and 7 show the tracks of the Jason-1 satellite in ascending and descending orbits and the spatial distribution of the data used. Because of the large amount of data generated by the $1 \mathrm{~Hz}$ sampling rate of the Jason-1 satellite, we used the median in $18 \mathrm{~s}$ to smooth the data; the satellite can advance to about $1^{\circ}$ during this period. From 13 to 18 May, the period at which the Jason-1 satellite's ascending orbit went through the region near South Africa was 21:00 UT to 04:00 UT the next day at 03:00 LT to 04:00 LT; the period at which the satellite's descending orbit went through South Africa was 10:00 UT to 18:00 UT at 15:00 LT to 16:00 LT. Figure 6 shows poor data on the satellite's ascending orbit, and that data distribution is sparse after smoothing. By contrast, the figure shows fine data on the satellite's descending orbit, and that data distribution is dense after smoothing.

Figures 6 and 7 show the VTEC changes when the Jason1 satellite is in ascending and descending orbits from 13 to 18 May 2005. Compared with the VTEC on 13 May, when space was at its calmest, the ascending orbit VTEC from 14 to 18 May showed no significant changes. On 15 May, when the magnetic storm's maximum main phase occurred, the Jason-1 satellite in the ascending orbit model appeared in the study region at 00:30 UT, 02:30 UT, 04:30 UT, 21:00 UT, and 23:00 UT. The analysis of the Jason-1 satellite data is consistent with the CIT analysis. On 15 May, the Jason-1 satellite in the descending orbit appeared in the study region

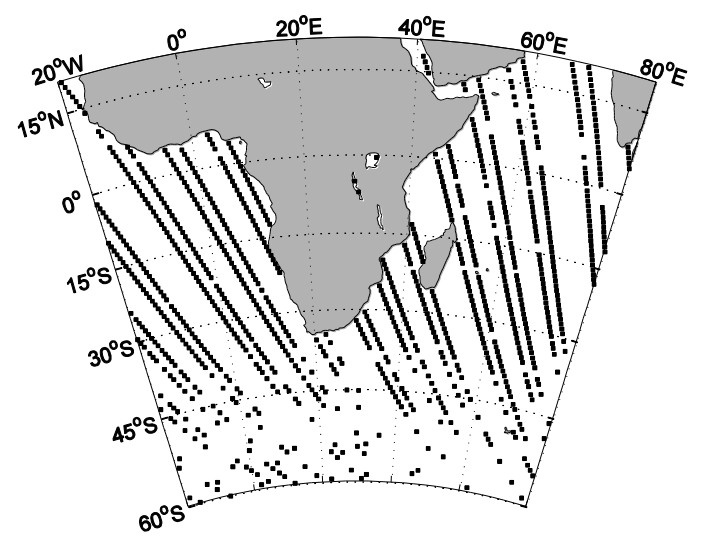

Fig. 7. Descending orbit data image taken by the Jason-1 satellite from 13 to 18 May 2005.

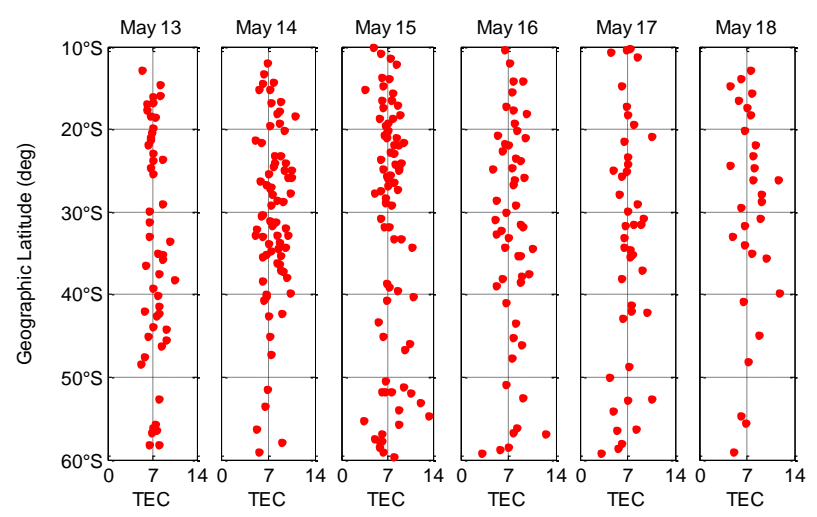

Fig. 8. Changes in the VTEC data obtained by the Jason-1 satellite in the ascending orbit from May 13 to 18 .

at 11:00 UT, 13:00 UT, 15:00 UT, 16:45 UT, and 19:00 UT. Compared with the VTEC obtained in the descending orbit from 13 to 18 May, the one obtained on 15 May significantly increased at certain periods. The expanded area covers $10^{\circ} \mathrm{S}$ to $35^{\circ} \mathrm{S}$, and the related VTEC data were obtained by the satellite at 11:00 UT and 16:00 UT. At 11:00 UT, the satellite orbit was in the area from $0^{\circ} \mathrm{S}$ to $20^{\circ} \mathrm{S}$ and $74^{\circ} \mathrm{E}$ to $80^{\circ} \mathrm{E}$. At 15:00 UT, the satellite orbit was in the area from $10^{\circ} \mathrm{S}$ to $45^{\circ} \mathrm{S}$ and $74^{\circ} \mathrm{E}$ to $10^{\circ} \mathrm{E}$. The results of the CIT inversion also revealed that significant positive anomalies occurred in the ionosphere at these periods. The VTEC data obtained by the satellite at 13:00 UT and 15:00 UT only minimally changed. Figure 10 shows the VTEC observations and tracks of the Jason-1 satellite in the descending orbit model on 15 May. The analysis of VTEC data is consistent with the CIT analysis. 


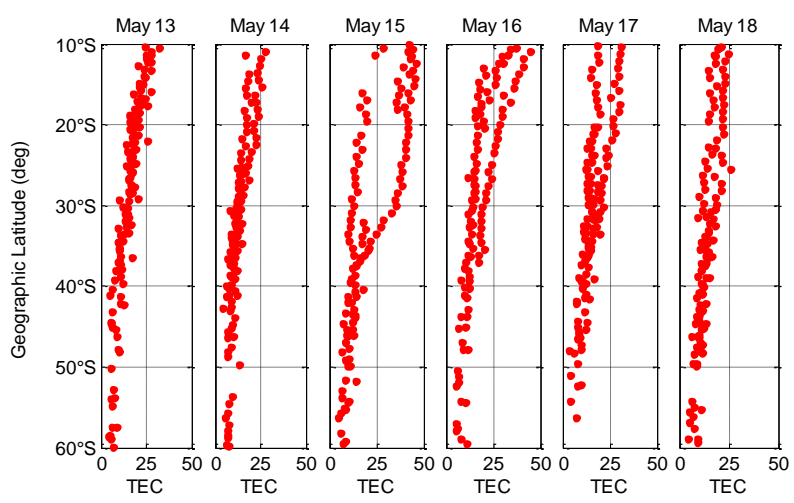

Fig. 9. Changes in the VTEC data obtained by the Jason-1 satellite in the descending orbit from 13 to 18 May.

\section{Conclusions}

We used the GNSS observations of the South African TrigNet to inverse the 3-D temporal and spatial variations in ionospheric electron density in South Africa during the strong magnetic storm on 15 May 2005. We compared the electron density distributions at different altitudes and longitudes on 14-15 May 2005. The electron density at any altitude at 10:00 UT on 15 May significantly increased compared with that on 14 May, indicating that a positive-phase storm occurred in the ionosphere of the inversion region during the magnetic storm. The maximum electron density at each altitude at 10:00 UT on 15 May increased to $79.3 \%$ on average compared with that on 14 May, at which the electron density at an altitude of $800 \mathrm{~km}$ increased to a maximum of $84.9 \%$. This increase is similar to the changes in electron density at any longitude.

To describe the process by which ionospheric electron density changed with time during the magnetic storm, we presented the electron density distribution at an altitude of $350 \mathrm{~km}$ and a longitude of $24^{\circ} \mathrm{E}$ at a time interval of $2 \mathrm{~h}$ from 04:00 UT on 14 May to 20:00 UT on 15 May. The inversion results precisely reflect the 3-D fine structure of ionospheric electron density and its response to the development of the magnetic storm. We determined the strong ionospheric disturbances during the magnetic storm and identified the characteristics of the changes in ionospheric electron density at the middle and low latitudes of the Southern Hemisphere. The ionospheric activity was strongly related to latitude, and the total electron density decreased with increasing latitude.

We also used VTEC data from Jason- 1 to analyze the ionospheric changes before and after the magnetic storm. The VTEC from the descending orbit during the magnetic storm on 15 May significantly increased compared with that on 14 May, whereas the VTEC from the ascending orbit presented insignificant changes. The time of occurrence and distribution of the anomalies are consistent with of the CIT results.

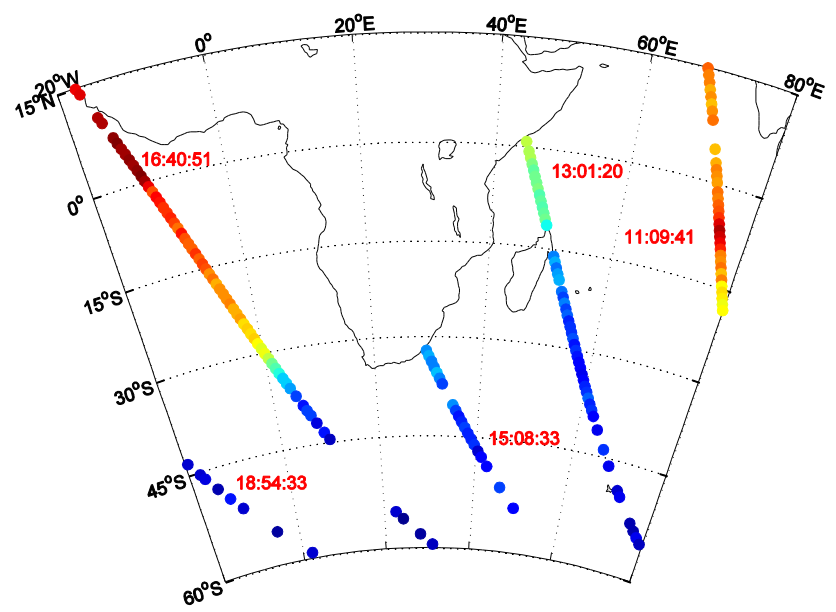

Fig. 10. The descending orbit of the Jason-1 satellite and the VTEC observations on the study region on May 15 .

Acknowledgements. The authors thank the IGS for providing GNSS observations, TripNet for providing observations on South Africa, IUGG for providing Kp and Dst indices, NASA for providing IRI2007 model data, CNES for providing Jason-1 observations, NOAA OSTM for providing Jason-2 observations, and NASA OMNIWEB for providing solar and geomagnetic indices. This work was supported by the Foundation for Innovative Research Groups of the National Natural Science Foundation of China (40721001) and the National Natural Science Foundation of China (41174012 and 41274022).

Edited by: A. Costa

Reviewed by: two anonymous referees

\section{References}

Appleton, E. and Ingram, L.: , Magnetic storms and upper atmospheric ionization, Nature, 136, 548-549, 1935.

Balan, D., Balaure, V., and Veghes, C.: Travel and tourism competitiveness of the world's top tourismdestinations: An exploratory Assessment, Annales Universitatis Apulensis series Oeconomica, 11, 979-987, 2009.

Balan, N. and Rao, P. B.: Dependence of ionospheric response on the local time of sudden commencement and the intensity of geomagnetic storms, J. Atmos. Terrest. Phys., 52, 269-275, 1990.

Balan, N., Shiokawa, K., Otsuka, Y., Kikuchi, T., Vijaya Lekshmi, D., Kawamura, S., Yamamoto, M., and Bailey, G. J.: A physical mechanism of positive ionospheric storms at low latitudes and midlatitudes, J. Geophys. Res., 115, A02304, doi:10.1029/2009JA014515, 2010.

Balan, N., Yamamoto, M., Sreeja, V., Batista, I. S., Lynn, K. J. W., Abdu, M. A., Ravindran, S., Kikuchi, T., Otsuka, Y., Shokawa, K., Alex, S.: A statistical study of the response of the dayside equatorial F2 layer to the main phase of intense geomagnetic storms as an indicator of penetration electric field, J. Geophys. Res., 116, A03323, doi:10.1029/2010JA016001, 2011. 
Blewitt, G.: An automatic editing algorithm for GPS data, Jet Propulsion, 17, 199-202, 1990.

Burns, A. G., Killeen, T. L., Deng, W., Carignan, G. R., and Roble, R. G.: Geomagnetic Storm Effects in the Low- to MiddleLatitude Upper Thermosphere, J. Geophys. Res., 100, 1467314691, 1995.

Dumont, J. P., Rosmorduc, V., Picot, N., Desai, S., Bonekamp, H., Figa, J., Lillibridge, J., and Scharroo, R.: OSTM/Jason-2 products handbook, 2009.

Essex, E. A., Mendillo, M., Schödel, J. P., Klobuchar, J. A., da Rosa, A. V., Yeh, K. C., Fritz, R. B., Hibberd, F. H., Kersley, L., Koster, J. R., Matsoukas, D. A., Nakata, Y., and Roelofs, T. H.: A global response of the total electron content of the ionosphere to the magnetic storm of 17 and 18 June 1972, J. Atmos. Terr. Phys., 43, 293-306, 1981.

Fu, L. L., Christensen Jr., E., Lefebvre, C. Y., Meacutenard, M., Dorrer, Y. M., and Escudier, P.: TOPEX/POSEIDON mission overview, J. Geophys. Res., 99, 24369-24381, 1994.

Fuller-Rowell, T. J., Codrescu, M. V., Moffett, R. J., and Quegan, S.: Response of the Thermosphere and Ionosphere to Geomagnetic Storms, J. Geophys. Res., 99, 3893-3914, 1994.

Jee, G., Schunk, R. W., and Scherliess, L.: Analysis of TEC data from the TOPEX/Poseidon mission, J. Geophys. Res., 109, 117, 2004.

Kelley, M. C., Vlasov, M. N., Foster, J. C., and Coster, A. J.: A quantitative explanation for the phenomenon known as stormenhanced density, Geophys. Res. Lett., 31, L19809, doi:10.1029/2004GL020875, 2004.

Lekshmi, V. D., Balan, N., Tulasi Ram, S., and Liu, J. Y.: Statistics of geomagnetic storms and ionospheric storms at low and mid latitudes in two solar cycles, J. Geophys. Res., 116, A11328, doi:10.1029/2011JA017042, 2011.

Lin, C. H., Richmond, A. D., Heelis, R. A., Bailey, G. J., Lu, G., Liu, J. Y., Yeh, H. C., and Su, S. Y.: Theoretical study of the low- and midlatitude ionospheric electron density enhancement during the October 2003 superstorm: Relative importance of the neutral wind and the electric field, J. Geophys. Res., 110, A12312, doi:10.1029/2005JA011304, 2005.

Lu, G., Goncharenko, L. P., Richmond, A. D., Roble, R. G., and Aponte, N.: A dayside ionospheric positive storm phase driven by neutral winds, J. Geophys. Res., 113, A08304, doi:10.1029/2007JA012895, 2008.

Lu, G., Goncharenko, L., Nicolls, M. J., Maute, A., Coster, A., and Paxton, L. J.: Ionospheric and thermospheric variations associated with prompt penetration electric fields, J. Geophys. Res., 117, A08312, doi:10.1029/2012JA017769, 2012.

Mai, C. L. and Kiang, J. F.: Reconstruction of Ionospheric Perturbation Induced by 2004 Sumatra Tsunami Using a Computerized Tomography Technique, IEEE Trans. Geosci. Remote Sens., 47, 3303-3312, 2009.
Mannucci, A. J., Tsurutani, B. T., Iijima, B. A., Komjathy, A., Saito, A., Gonzalez, W. D., Guarnieri, F. L., Kozyra, J. U., and Skoug, R.: Dayside global ionospheric response to the major interplanetary events of October 28-30, 2003 Halloween Storms 8221, Geophys. Res. Lett., 32, L12S02, doi:10.1029/2004GL021467, 2005.

Mendillo, M. and Narvaez, C.: Ionospheric storms at geophysicallyequivalent sites - Part 1: Storm-time patterns for subauroral ionospheres, Ann. Geophys., 27, 1679-1694, doi:10.5194/angeo-27-1679-2009, 2009.

Mendillo, M. and Narvaez, C.: Ionospheric storms at geophysicallyequivalent sites - Part 2: Local time storm patterns for sub-auroral ionospheres, Ann. Geophys., 28, 1449-1462, doi:10.5194/angeo-28-1449-2010, 2010.

Paul, M. P., Matsushita, S., and Richmond, A. D.: Ionospheric storm of 4-5 August 1972 in the Asia-Australia-Pacific sector, J. Atmos. Terr. Phys., 39, 43-50, 1977.

Richmond, A. D. and Matsushita, S.: Thermospheric Response to a Magnetic Substorm, J. Geophys. Res., 80, 2839-2850, 1975.

Szuszczewicz, E. P., Lester, M., Wilkinson, P., Blanchard, P., Abdu, M., Hanbaba, R., Igarashi, K., Pulinets, S., and Reddy, B. M.: A comparative study of global ionospheric responses to intense magnetic storm conditions, J. Geophys. Res., 103, 11665-11684, 1998.

Thampi, S. V., Lin, C., Liu, H., and Yamamoto, M.: First tomographic observations of the Midlatitude Summer Nighttime Anomaly over Japan, J. Geophys. Res., 114, 1-10, 2009.

Wen, D. B., Yuan, Y. B., On, J. K., Huo, X. L., and Zhang, K. F.: Ionospheric temporal and spatial variations during the 18 August 2003 storm over China, Earth Planet. Space, 59, 313-317, 2007.

Yao, Y. B., Chen, P., Wu, H., Zhang, S., and Peng, W. F.: Analysis of ionospheric anomalies before the $2011 \mathrm{M}-\mathrm{w} 9.0$ Japan earthquake, Chinese Sci. Bull., 57, 500-510, 2012a.

Yao, Y. B., Chen, P., Zhang, S., Chen, J. J., Yan, F., and Peng, W. F.: Analysis of pre-earthquake ionospheric anomalies before the global $M=7.0+$ earthquakes in 2010, Nat. Hazards Earth Syst. Sci., 12, 575-585, doi:10.5194/nhess-12-575-2012, 2012 b.

Yeh, K., Ma, S., Lin, K., and Conkright, R.: Global ionospheric effects of the October 1989 geomagnetic storm, J. Geophys. Res., 99, 6201-6218, 1994.

Yizengaw, E., Dyson, P. L., Essex, E. A., and Moldwin, M. B.: Ionosphere dynamics over the Southern Hemisphere during the 31 March 2001 severe magnetic storm using multi-instrument measurement data, Ann. Geophys., 23, 707-721, doi:10.5194/angeo23-707-2005, 2005.

Zhao, B. Q.: Studies on the annual and semiannual anomalies and storm characteristics of mid- and low latitudes ionosphere, Ph.D. dissertation, Wuhan Institute of Physics and Mathematics \& Institute of Geology and Geophysics, Chinese Academy of Sciences, 2006. 